\title{
Effect of Linear Chain Carboxylic Acid Anhydrides on Physical and Mechanical Properties of Rubber (Hevea brasiliensis), Acacia, (Acacia spp.), and Oil Palm (Tinnera spp.) Woods
}

\author{
Mohd Afiq Mohtar, ${ }^{1}$ Norul Hisham Hamid, ${ }^{1}$ and Mohd Hamami Sahri ${ }^{2}$ \\ ${ }^{1}$ Faculty of Forestry, University Putra Malaysia, 43400 Serdang, Selangor Darul Ehsan, Malaysia \\ ${ }^{2}$ School International Tropical Forestry (SITF), University Malaysia Sabah, Jalan UMS, 88400 Kota Kinabalu, Sabah, Malaysia \\ Correspondence should be addressed to Mohd Afiq Mohtar; mohd87afiq@gmail.com
}

Received 24 January 2014; Revised 28 April 2014; Accepted 6 May 2014; Published 22 May 2014

Academic Editor: Yuanxin Zhou

Copyright ( $) 2014$ Mohd Afiq Mohtar et al. This is an open access article distributed under the Creative Commons Attribution License, which permits unrestricted use, distribution, and reproduction in any medium, provided the original work is properly cited.

\begin{abstract}
The physical and mechanical properties of Rubber wood, Acacia wood, and Oil palm wood that reacted with acetic, propionic, and butyric anhydrides using a microwave heating for 4 minutes were investigated. A sample dimension of $300 \mathrm{~mm} \times 100 \mathrm{~mm} \times 25 \mathrm{~mm}$ $(L \times W \times T)$ was used for modification and they were cut into smaller specimens for different testing method. This study found that the density increment and void volume changes were not significantly different from anhydrides. The modification of wood with anhydrides was not significantly affected by the static bending properties, except for the Oil palm. The compression strength for any anhydrides shows an improvement for the Rubber wood and Acacia spp. but not Oil palm. The hardness was also not significantly different from anhydrides for all wood species. The impact strength of Rubber wood and Oil palm significantly increased compared to the untreated wood, but this was not the case for Acacia spp. Generally, the highest improvement in mechanical properties was obtained by modification of Rubber and Acacia woods with butyric anhydride.
\end{abstract}

\section{Introduction}

Rubber, Acacia, and Oil palm trees are the main supply for plantation wood in Malaysia. The Rubber and Acacia woods have been used for furniture and building materials, while Oil palm wood is used as inner layer of veneer for plywood. However, these wood species are vulnerable to the attack by microorganism such as fungi and termites if the products are used in extreme outdoor condition. In the long term, this will deteriorate its physical and mechanical properties and shorten the service life.

Chemical modification has been reported to improve dimensional stability and biological resistance of wood. This treatment is considered as nontoxic to human compared with conventional wood preservative. In chemical modification, the nontoxic compounds get attached into the wood structure and the toxicity problem can be shunned $[1,2]$.

Wood treated with chemicals such as methyl ether, epoxides, and aldehyde degraded its mechanical properties compared with untreated wood [3]. However, modifying wood with acetic anhydride improves dimensional stability as well as its biological and weathering resistances but gave a little effect on the strength properties of wood $[2,4]$. However, there was concern over the influences of acetylation on the strength properties of wood due to its by-product of acetic acid, which resulted either in the reduction of fibre and lignocellulose contents or in a possibility of hydrothermal effect $[5,6]$.

A comprehensive study on the bending strength of acetylated Scandinavian softwood from pine (Pinus sylvestris L.) and spruce (P. abies Karst.) was conducted [7]. The wood was acetylated in acetic anhydride without addition of catalyst or organic cosolvent to WPGs of 19.1, 18.2, and 23.3 for pine. The study indicated that only small changes in bending strength occurred in acetylated woods. Acetylated pine had a higher Brinell hardness in both directions compared to unmodified wood. The study of acetylation of solid wood using microwave by [8] proved that, at a higher level of 
acetylation, both MOR and MOE values decreased compared to the lower acetylation level. The lower EMC of acetylated wood compared to untreated wood was one of the factors that influenced the strength properties of the modified wood. The result of higher level of acetylation caused the reduction of MOR and MOE values [9]. The tensile strength of preconditioned wood and the work to failure of acetylated woods were found to not be significantly different from the unmodified controls [10]. Acetylation did not significantly affect the mechanical properties of the softwood (pine, spruce, and larch) [11]. Acetylation of Scots pine at $145^{\circ} \mathrm{C}$ for four hours gave a $50 \%$ reduction in tensile modulus [12].

The objective of this study is to evaluate the mechanical properties of modified Rubber, Acacia, and Oil palm wood with linear chain carboxylic anhydrides using a microwave.

\section{Experimental}

2.1. Preparation and Selection of Samples. The 25 years old Rubber, Acacia, and Oil palm woods were randomly selected and used in this study. The Rubber wood was obtained from Seng Yip Furniture Sdn. Bhd. The Acacia wood was obtained from Pallet factory at Jalan Reko, Kajang, Selangor, and Oil palm wood from Felda Jengka 25 Pahang. The woods were cut and trimmed into sample size of $300 \mathrm{~mm} \times 100 \mathrm{~mm} \times 25 \mathrm{~mm}$ $(L \times W \times T)$ and oven-dried at $103^{\circ} \mathrm{C}$ for 24 hours .

2.2. Impregnation and Reaction of Samples. The impregnation process was conducted using a dipping-vacuum-pressure method. The specimens were arranged separately by species and anhydride. The three different anhydrides used were acetic, propionic, and butyric anhydrides. The samples were submerged in the anhydrides, ballasted with steel wrapped with aluminium in a steel container. The container containing submerged sample was inserted at the bottom of the vacuum vessel. The vacuum was applied for 20 minutes and slowly released to allow the atmospheric impregnation to occur. After vacuum process, the submerged specimens were pressured at $0.8 \mathrm{MPa}$ for 30 minutes using air compressor, released, repressured for another 15 minutes, and released again. The amount of anhydrides uptake was calculated by comparing the weight of specimen before and after impregnation. The amount of anhydrides uptake was expressed as percentage uptake (\%) and was calculated using the following formula [2]:

$$
\mathrm{PU}(\%)=\left[\frac{\left(W_{1}-W_{0}\right)}{W_{0}}\right] \times 100,
$$

where $W_{1}$ is the weight of the sample after impregnation and $W_{0}$ is weight of the sample before impregnation.

2.2.1. Reaction and Postdrying of Samples. The impregnated wood was transferred into microwave and the reaction was conducted for 2 and then 4 minutes using a Panasonic Microwave (NN-CD997S) with $2450 \mathrm{MHz}$ frequency and $50 \mathrm{~W}$ output. After 2 minutes, the reacted wood was taken out from microwave to measure its weight and volume and then the samples were reacted again for another 2 minutes.
This procedure was to minimize the damage/crack of the samples. It was previously observed that the crack occurred when the wood reacted for more than 4 minutes. The weight and volume were measured again to calculate the bulking coefficient (BC). The BC was calculated using the following formula [2]:

$$
\mathrm{BC}(\%)=\left[\frac{\left(V_{m}-V_{u}\right)}{V_{u}}\right] \times 100
$$

where $V_{u}$ is the volume of the unmodified wood sample and $V_{m}$ is the volume of the modified wood sample.

After the reaction procedures, the modified wood was submerged in cold acetone solution in a steel container for 24 hours to stop the reaction. The acetone was removed and the container which contained reacted wood was vacuumed again to remove unreacted anhydrides and other residues using the impregnation chamber. Finally, the modified wood was oven-dried at $70^{\circ} \mathrm{C}$ for 24 hours to determine its final weight gain (WPG). The WPG was calculated using the following formula [2]:

$$
\operatorname{WPG}(\%)=\left[\frac{\left(M_{m}-M_{u}\right)}{M_{u}}\right] \times 100,
$$

where $M_{m}$ is the oven-dry mass of the modified wood and $M_{u}$ is the oven-dry mass of the unmodified wood.

\subsection{Density Increment and Percent Void Volume Changes.}

The density of the sample before and after the reaction procedures was taken to calculate the density increment of each modified sample. The density increment of modified wood was calculated using the following formula (see [4]):

$$
\text { Density increment }(\%)=\left[\frac{\left(D_{1}-D_{0}\right)}{D_{0}}\right] \times 100 \text {, }
$$

where $D_{1}$ is the density of the wood after being modified and $D_{0}$ is the density of the wood before being modified.

The percent void volume was also calculated to measure the void volume of the wood before and after modification takes place. The percent void volume of wood before and after modification; and percent void volume changes were calculated using the following formula [13]:

$$
\% \text { Void volume }=\left(\frac{1-S^{\text {od }}}{1.5}\right) \times 100
$$

where $\mathrm{SG}^{\text {od }}$ is the specific gravity of the wood before or after modification and

$$
\text { \%Void vol. changes }=\left[\frac{\left(\mathrm{VM}^{m}-\mathrm{VM}^{\mathrm{um}}\right)}{\mathrm{VM}^{\mathrm{um}}}\right] \times 100,
$$

where $\mathrm{VM}^{m}$ is the void volume of modified wood and $\mathrm{VM}^{\mathrm{um}}$ is the void volume of unmodified wood.

2.4. Testing Method. The untreated and modified woods were cut into different sizes according to the standard. The 
mechanical properties (static bending test, compression test, hardness test, and impact test) were tested according to BS Standards [14] using the INSTRON Universal Testing Machine. All modified and control wood were subsequently conditioned at $65 \pm 5 \% \mathrm{RH}$ and $20 \pm 3^{\circ} \mathrm{C}$ for one week prior to test.

2.4.1. Static Bending Test. The static bending was tested according to $2 \mathrm{~cm}$ standard [14]. The modulus of rupture $(\mathrm{MoR})$ and modulus of elasticity (MoE) values were obtained from the strain-stress curve. The test was carried out by using the central loading method or three-point flexure test. The test was performed according to BS 373:1957 standards using Instron universal testing machine with load capacity of $50 \mathrm{kN}$. The dimensions were $30 \mathrm{~cm} \times 2 \mathrm{~cm} \times 2 \mathrm{~cm}(L \times W \times T)$. The orientation of the annual rings of the test piece was parallel to the direction of loading. The distance between the points of support of the test piece was $28 \mathrm{~cm}$. The crosshead speed was $0.249 \mathrm{in} / \mathrm{min}$. The data were recorded in the control panel, and the MOR and MOE values were automatically calculated.

2.4.2. Compression Strength Test. The compression strength parallel to the grain was tested according to the $2 \mathrm{~cm}$ standard [14]. The specimen dimension of $60 \mathrm{~mm} \times 20 \mathrm{~mm} \times 20 \mathrm{~mm}$ $(L \times W \times T)$ was prepared and the test was conducted at crosshead speed of $0.6350 \mathrm{~mm} / \mathrm{min}$. The test piece was placed vertically parallel to the grain with the load direction. The data was automatically calculated by the control panel of the Instron machine.

2.4.3. Hardness Test. The hardness strength was tested using the Janka indentation test according to the $2 \mathrm{~cm}$ standards [14]. The test required the determination of the load necessary to force into the test piece to a depth of 0.222 inch by a hemispherical end of a steel ball with diameter of 0.002 inch. The specimen dimension of $60 \mathrm{~mm} \times 20 \mathrm{~mm} \times 20 \mathrm{~mm}(L \times$ $W \times T)$ was placed at the center of a solid wood plank designed for this test. The rate of penetration of the hardness tool was $0.25 \mathrm{inch} / \mathrm{min}$. Once the test was started, the pin was pulled and pushed constantly towards and backwards horizontally until the test cycle was completed and the data were recorded.

2.4.4. Impact Strength Test. The amount of energy (Joule) absorbed during fracture was determined by the impact tester. The Charpy method was used in this test. The test piece was placed at the middle of the support; a 5-Joule hammer was free-fell perpendicularly into the middle point of the specimen sized $120 \mathrm{~mm} \times 10 \mathrm{~mm} \times 10 \mathrm{~mm}(L \times W \times T)$ at the $150^{\circ}$ angle spin. The data of impact were automatically calculated by the Instron impact tester machine.

2.4.5. Data Analysis. The data collected from the testing procedures were analyzed using a statistical analysis software SPSS version 14. The data of the basic and mechanical properties were analyzed according to 0.05 probability level according to the Waller-Duncan test. The correlation relation test ( $R$ value) between the basic properties of modified wood

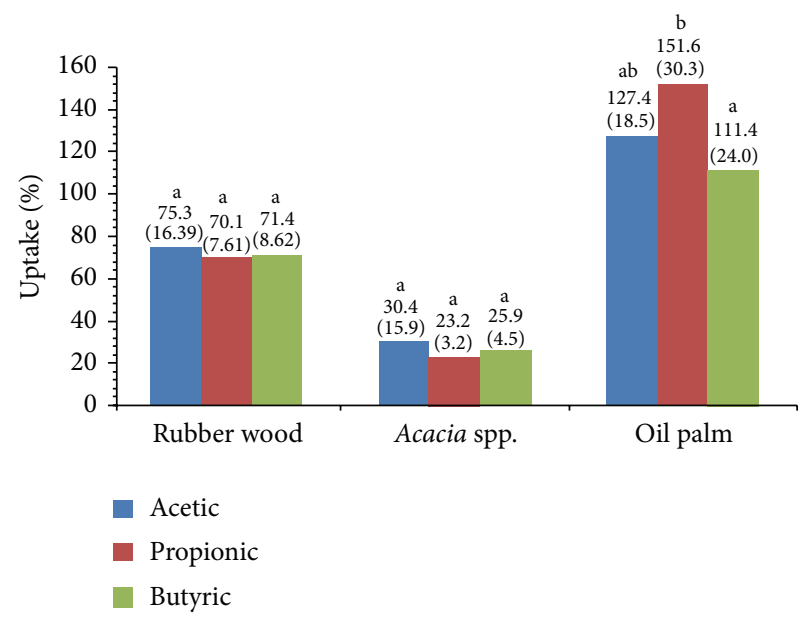

FIGURE 1: The percentage of solution uptake of woods modified with different anhydrides. Figures in the parentheses are standard deviations. Means followed by the same letter(s) in the same bar are not significantly different at the 0.05 probability level according to the Waller-Duncan test.

with PU, WPG, and BC and the correlation test between the basic and physical properties of modified wood with the mechanical properties of modified wood were also calculated using the same software.

\section{Results and Discussion}

\subsection{Physical Properties}

3.1.1. Percentage Uptake. Regardless of anhydrides (Figure 1), the Oil palm wood took up the highest anhydride solutions followed by Rubber wood and Acacia spp., which indicated its highest permeability. In Oil palm, the percentages uptake were significantly higher for propionic (151.6\%) followed by acetic $(127.4 \%)$ and butyric (111.4\%) anhydrides. From Figure 5, the percentage void volume before modification in Oil palm was highest among the three species which leads to its highest solution uptake. In Rubber wood, the percentages of uptake were not significantly different from the anhydrides. The averages were $75.3 \%$ (acetic anhydride), $70.1 \%$ (propionic anhydride), and 71.4\% (butyric anhydride), respectively. In Acacia spp., the percentages uptake were also not significantly different from anhydrides ranging between $30.4 \%$ (acetic anhydride), 23.2\% (propionic anhydride), and $25.9 \%$ (butyric anhydride). This indicates that the molecular weight of anhydrides was not influenced by the uptake in both Rubber wood and Acacia spp.

3.1.2. Bulking Coefficient. Overall, the modified Rubber wood had a higher bulking coefficient followed by Acacia spp. and Oil palm woods, except for butyric anhydride (Figure 2). The bulking coefficient of Rubber wood modified with butyric anhydride (4.93) was almost identical to that of Acacia spp. (4.92). The bulking coefficient was not significantly different from the anhydrides for Acacia and Oil palm woods, but not in the case of Rubber wood. The Rubber wood 


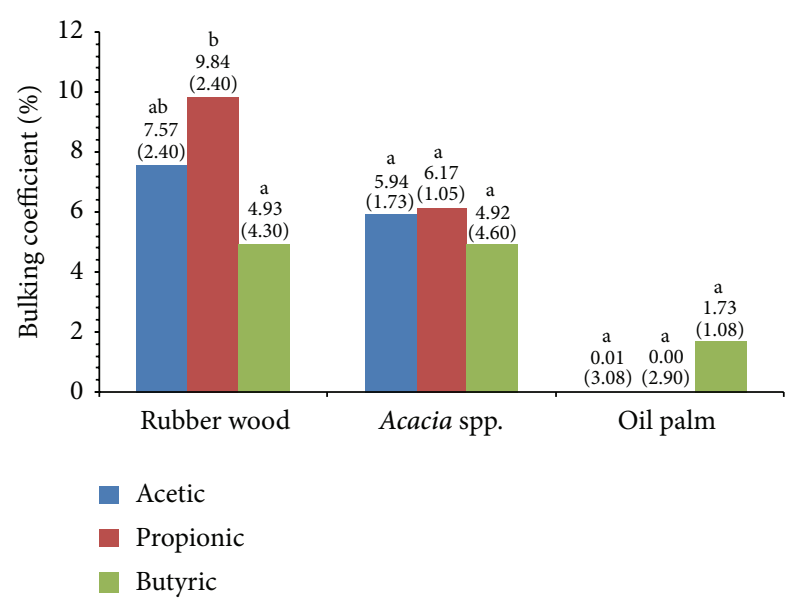

FIGURE 2: The bulking coefficiency of woods modified with different anhydrides. Figures in the parentheses are standard deviations. Means followed by the same letter(s) in the same bar are not significantly different at the 0.05 probability level according to the Waller-Duncan test.

modified with propionic anhydride $(9.84 \%)$ gave the highest bulking coefficient followed by acetic (7.57\%) and butyric anhydrides (4.93\%). However, the trends for bulking were not in harmony with the increasing of anhydrides molecular weight. Therefore, the molecular weight of anhydrides did not give any increment to bulking coefficient. For comparison, the maximum bulking coefficient of acetylated and hexanoic Corsican pine at 25 WPG was $12 \%$ and $14 \%$, respectively [15]. The maximum bulking coefficient of acetylated rattan after 10 hours reaction was ranged from 7.4 to 8.1 [16], which was higher than modified Acacia and Oil palm woods. Bulking coefficient or volume changes due to modification were due to the volume occupied by the reagent and associated void volume [15].

3.1.3. Weight Percentage Gain. In contrast with uptake, the percentage weight gain was highest in Rubber wood followed by Oil palm and Acacia woods for all anhydrides (Figure 3). This generally means that the reactivity of Rubber wood with anhydrides was greater than Acacia and Oil palm. Chemical modification of wood can be defined as any chemical reaction between some reactive part of a wood cell wall component and a simple single chemical reagent, with or without catalyst that forms a covalent bond between the two components. Therefore, the amount of chemical constituents for each wood species influenced percentage WG. Among the structural chemical components, cellulose was the fastest to react with acetic anhydride followed by hemicelluloses and lastly lignin [17-19]. However, only $35 \%$ of hydroxyl groups in amorphous cellulose are accessible for reaction and the remaining $65 \%$ is inaccessible crystalline cellulose [20]. The highest WG obtained in Rubber wood was probably caused by its higher hemicelluloses and lignin contents as compared to Acacia and Oil palm woods (Table 1). Regardless of anhydrides, the averages weight gain range from 36.5 to $40.5 \%$ for Rubber wood, from 15.2 to $24.2 \%$ were for Oil palm wood

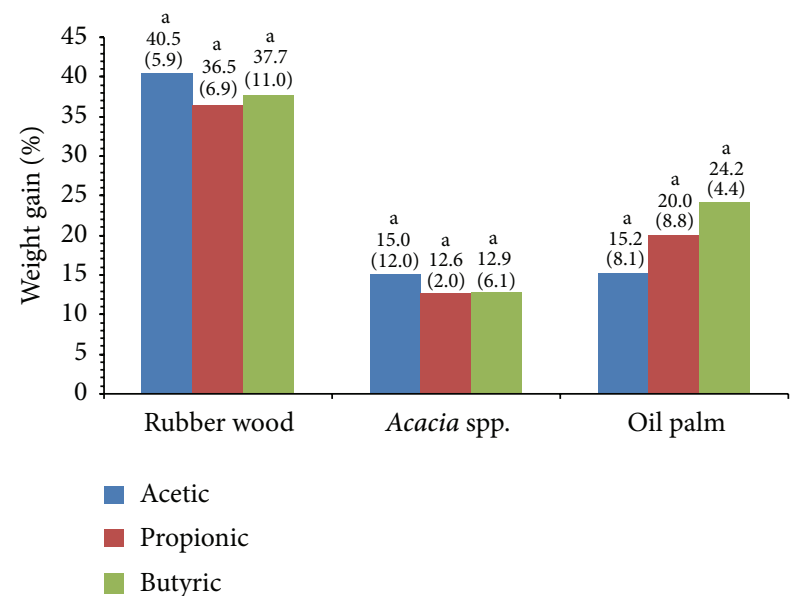

FIGURE 3: The weight percentage gain of woods modified with different anhydrides. Figures in the parentheses are standard deviations. Means followed by the same letter(s) in the same bar are not significantly different at the 0.05 probability level according to the Waller-Duncan test.

TABLE 1: The structural chemical constituents of Rubber wood, Acacia spp., and Oil palm.

\begin{tabular}{lccc}
\hline Chemical & Rubber wood [23] & Acacia spp. [24] & $\begin{array}{c}\text { Oil palm } \\
{[25]}\end{array}$ \\
\hline$\alpha$-Cellulose (\%) & 40 & 46.5 & 41.02 \\
Hemicellulose (\%) & 30 & 24.4 & 22.04 \\
Lignin (\%) & $22-29$ & 27.51 & 24.51 \\
\hline
\end{tabular}

and 12.6 to $15.0 \%$ were for Acacia wood. This indicates that the anhydrides molecular weight was not significantly influenced by the weight gain for each wood species. For comparison, acetylation of Pine wood sized $4.5 \times 12 \times 14 \mathrm{~cm}$ $(t \times r \times l)$ using a microwave $(460 \mathrm{~W})$ had a maximum $20 \mathrm{WPG}$ after 200 minutes reaction [21]. Modification of hinoki wood with acetic, propionic, butyric, isobutyric, and hexanoic anhydrides using a conventional heating method gave a maximum WPG ranging from 20 to 40 after reacting at temperature of $140^{\circ} \mathrm{C}$ for 24 hours [22]. Despite the oil palm and rattan are monocotyledon plants, the average WPG of modified oil palm for either anhydride was higher than acetylated rattan (14-15 WPG) reacting for 24 hours using conventional heating method [16]. This was probably due to lower hemicellulose (13-14.5\%) and lignin (17.3-19.4\%) contents in rattan compared to Oil palm.

3.1.4. Density Increment. The densities for all wood species were generally higher after being modified with any anhydrides (Figure 4). The density increments were found to not be significantly different from the anhydrides for all wood species, despite a slightly higher increment in propionated wood. The increment was largest in Rubber wood followed by Oil palm and Acacia woods, regardless of anhydrides. They ranged from $24.23 \%$ to $31.4 \%$ in modified Rubber wood, from $14.58 \%$ to $22.16 \%$ in modified Oil palm, and from $4.7 \%$ to $9.78 \%$ in modified Acacia wood. This indicates that 


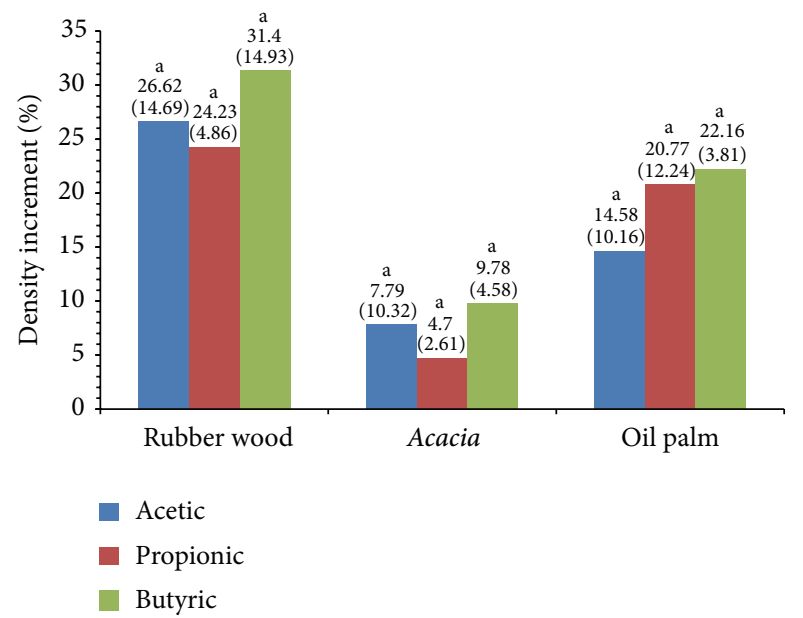

FIGURE 4: The density increment of woods modified with different anhydrides. Figures in the parentheses are standard deviations. Means followed by the same letter(s) in the same bar are not significantly different at the 0.05 probability level according to the Waller-Duncan test.

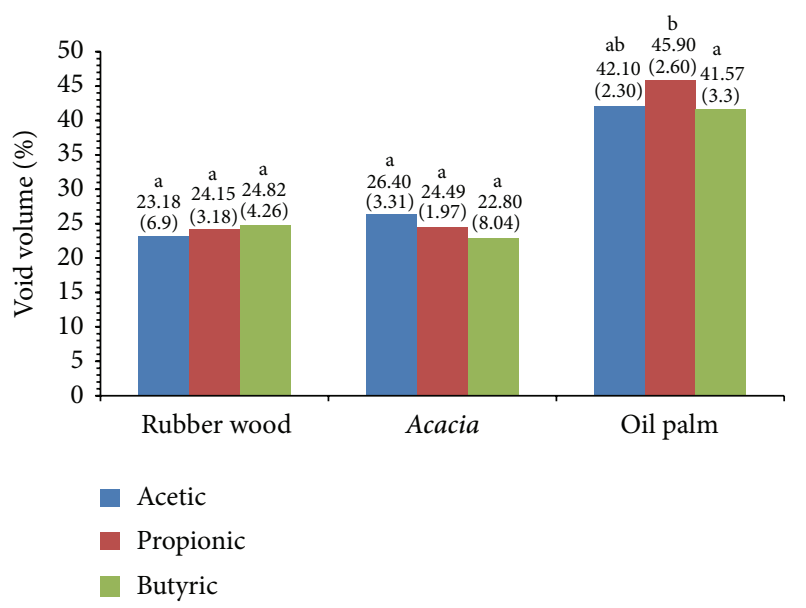

FIGURE 5: The average percentage void volume of untreated wood samples before modification. Figures in the parentheses are standard deviations. Means followed by the same letter(s) in the same bar are not significantly different at the 0.05 probability level according to the Waller-Duncan test.

the anhydrides molecular weight was not influenced by the density increment. The density increments of Rubber wood were highest among the three species which may probably be caused by its highest WPG. Even though Oil palm wood had the highest solution uptake, its reaction with the anhydrides was low which resulted in a low density increment. This was probably due to the fact that the Oil palm wood was not extracted with any solvents before reaction. Excess oil in the fiber and parenchyma cells may have probably obstructed reaction between the structural organic chemicals and anhydrides. A similar trend occurred with the Acacia samples.

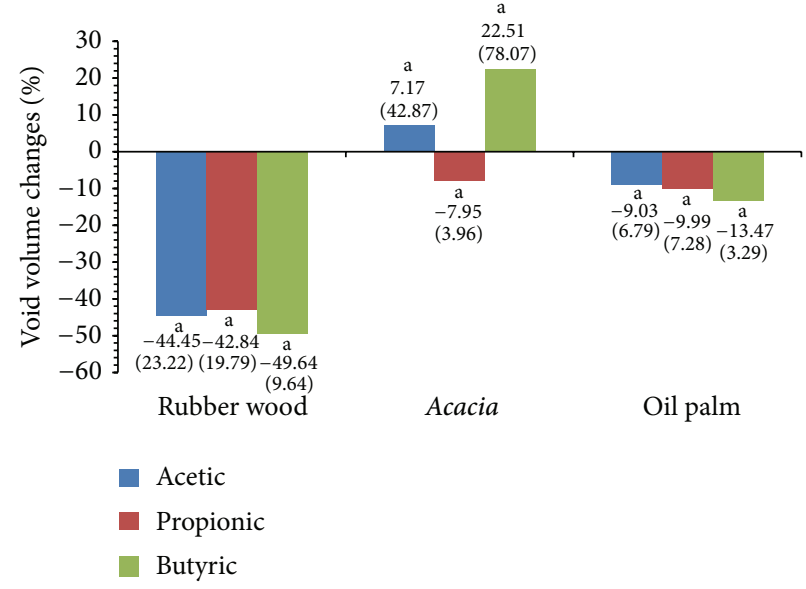

FIGURE 6: The void volume changes of woods modified with different anhydrides. Figures in the parentheses are standard deviations. Means followed by the same letter(s) in the same bar are not significantly different at the 0.05 probability level according to the Waller-Duncan test.

3.1.5. Void Volume Changes (\%). The untreated Oil palm wood had a higher percentage void volume than those of Rubber and Acacia woods. The average percentage void volume was ranged from 41.57 to 45.90 for Oil palm wood, from 22.80 to 26.40 for Acacia wood, and from 23.18 to 24.82 for Rubber wood. This was probably due to a lower density of Oil palm as compared to Rubber and Oil palm woods, which created more voids. The SEM image clearly showed the largest parenchyma and fiber lumen diameters in untreated Oil palm wood, as compared to Rubber and Acacia woods. The average percentage void volume of modified wood was not significantly different from anhydrides for all species, ranging from 36.04 to 41.43 for Oil palm wood, 22.53 to 27.52 for Acacia wood, and 12.03 to 13.87 for Rubber wood. This indicates that the percentage void volume of modified wood was not influenced by the anhydride molecular weights. The Rubber wood modified with any anhydrides had the highest percentage void volume changes followed by Oil palm and Acacia woods (Figure 6). The highest BC obtained by the modified Rubber wood may probably be caused by its lowest percentage void volume changes. In contrast, Acacia and Oil palm woods obtained a lower BC which may probably be caused by its higher percent void volume changes. The averages percentage void volume changes for modified woods were ranged from -49.64 to -42.84 for Rubber wood, from -13.47 to -9.03 for Oil palm wood, and from -7.95 to 22.51 for Acacia wood. The percentage void volume changes of Rubber and Oil palm woods modified with anhydrides were higher than that of acetylated rattan (ranged from -10.1 to 8.8) [16].

3.1.6. The Relationship between the Basic Properties of Modified Wood. The results of correlation test between the basic and physical properties of modified wood are listed in Table 2. The results were varied between the wood species. The uptake had a weak relation with the physical properties of modified Rubber and Acacia woods. The weight gain had a positive 
TABLE 2: The results of correlation test between the basic properties of modified wood.

\begin{tabular}{lccc}
\hline Properties & PU (\%) & WG (\%) & BC \\
\hline Rubber wood & & & \\
Density (after modification) & $-0.37^{\mathrm{Ns}}$ & $0.53^{*}$ & $-0.53^{*}$ \\
Density (increment) & $0.49^{\mathrm{Ns}}$ & $0.83^{* *}$ & $-0.65^{* *}$ \\
Void volume (after modification) & $0.38^{\mathrm{Ns}}$ & $-0.53^{*}$ & $0.53^{*}$ \\
Void volume changes & $-0.32^{\mathrm{Ns}}$ & $-0.81^{* *}$ & $0.59^{*}$ \\
Acacia spp. & & & \\
Density (after modification) & $0.14^{\mathrm{Ns}}$ & $0.13^{\mathrm{Ns}}$ & $0.07^{\mathrm{Ns}}$ \\
Density (increment) & $0.52^{\mathrm{Ns}}$ & $0.55^{\mathrm{Ns}}$ & $0.34^{\mathrm{Ns}}$ \\
Void volume (after modification) & $-0.15^{\mathrm{Ns}}$ & $-0.13^{\mathrm{Ns}}$ & $-0.07^{\mathrm{Ns}}$ \\
Void volume changes & $-0.32^{\mathrm{Ns}}$ & $-0.43^{\mathrm{Ns}}$ & $-0.5^{\mathrm{Ns}}$ \\
Oil palm & & & \\
Density (after modification) & $-0.71^{* *}$ & $0.69^{* *}$ & $-0.19^{\mathrm{Ns}}$ \\
Density (increment) & $-0.11^{\mathrm{Ns}}$ & $0.96^{* *}$ & $-0.54^{*}$ \\
Void volume (after modification) & $0.71^{* *}$ & $-0.69^{* *}$ & $0.19^{\mathrm{Ns}}$ \\
Void volume changes & $0.39^{\mathrm{Ns}}$ & $-0.93^{* *}$ & $0.38^{\mathrm{Ns}}$ \\
\hline
\end{tabular}

PU: percentage uptake, WG: weight gain, BC: bulking coefficient. Ns: not significant, ${ }^{*}$ significant at the 0.05 level, and ${ }^{* *}$ significant at the 0.01 level.

relation with the density after modification $(r=0.53)$ and increment $(r=0.83)$ but had a negative relation with void volume after modification $(r=-0.53)$ and changes $(r=$ -0.81 ) in both Rubber and Acacia woods. In modified Rubber wood, the bulking coefficient had a negative relation with the density after modification $(r=0.53)$ and increment $(r=0.83)$ but showed positive relation with void volume after modification $(r=0.53)$ and changes $(r=0.59)$. The bulking coefficient had a weak relationship with all the physical properties in modified Acacia and Oil palm woods (except the density increment).

\subsection{Mechanical Properties}

3.2.1. Static Bending. The modes of modulus of rupture (MoR) (Figure 7) and modulus of elasticity (MoE) (Figure 8) were almost identical for all modified wood, regardless of species. The untreated Acacia wood had a higher MoR and MoE followed by Rubber and Oil palm woods. The Rubber wood modified with acetic and propionic anhydrides had a significantly lower MoR and MoE than the untreated wood, but the untreated wood showed that it is not significantly different from butyric anhydride. The averages MoR and $\mathrm{MoE}$ of Acacia wood were not significantly different from the anhydrides, ranging from 93.12 to $98.16 \mathrm{MPa}$ and 9982.7 to $10960.2 \mathrm{MPa}$, respectively. The MoR and MoE of Oil palm wood modified with any anhydrides were significantly lower than the untreated wood. The MoR of Oil palm wood modified with anhydrides was ranged from 6.36 to $8.65 \mathrm{MPa}$, while it was $23.30 \mathrm{MPa}$ for untreated wood. The MoE of Oil palm wood modified with anhydrides was ranged from 387.2 to $497.9 \mathrm{MPa}$ and it was 2086.8 for untreated wood. This showed that the modification of wood with anhydrides was not impaired by the static bending properties, except

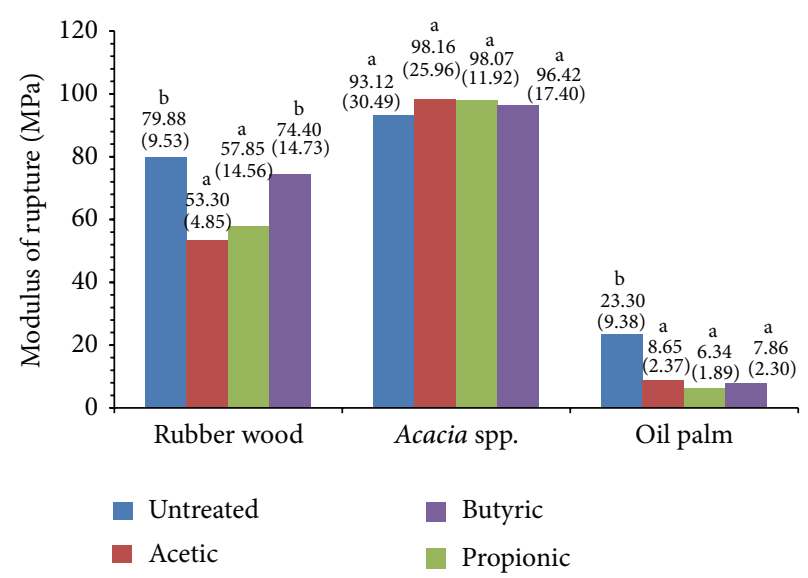

FIGURE 7: The modulus of rupture of woods modified with different anhydrides. Figures in the parentheses are standard deviations. Means followed by the same letter(s) in the same bar are not significantly different at the 0.05 probability level according to the Waller-Duncan test.

for the Oil palm wood. The effect of anhydrides molecular weight was not significantly influenced by the static bending properties. The decrease in MoR and MoE observed was maybe due to the modification process. The process of modification that includes heat treatment such as reaction in microwave may cause a certain degree of degradation on the wood and result in strength loss. The reduction in MoR and $\mathrm{MoE}$ was probably due to the lower moisture content of modified wood. Since the wood was conditioned prior to testing, the MC of untreated wood was increased due to the humidity and this effect was less likely to occur for the modified wood. The same result was obtained by modifying Pine (Pinus sylvestris. L.) [7]. Acetylated radiata pine (Pinus radiata) in structural sizes was not significantly different in the MoE, but the MoR is slightly less compared to the untreated wood; however, these comparisons were difficult due to high variation [6]. In relation to the reaction system, the MoR of acetylated Sitka spruce (Picea sitchensis) increased with increasing WPG, but it was slightly lower in the xylene system compared to pyridine system and uncatalyzed system. The MoE was not significantly different from the reaction system [26]. The MoR and MoE in finger jointed acetylated beech wood (Fagus sylvatica) decreased by $141 \%$ and $63 \%$ compared to the untreated samples [27]. The variation in mechanical properties of acetylated wood is probably caused either by reduction of moisture content (i.e., lower EMC values) or as a result of lowering of cross-sectional area or as a result of cell wall degradation caused by prolonged reaction times $[2,28]$. Acetylation will cause the wood to become swell and will lead to fewer load-bearing fibers within the crosssectional area [8].

3.2.2. Compression Strength. The average compression strength (Figure 9) was significantly different from the anhydrides for Rubber and Oil palm woods but not in the case of Acacia wood. In Rubber wood, the average compression 


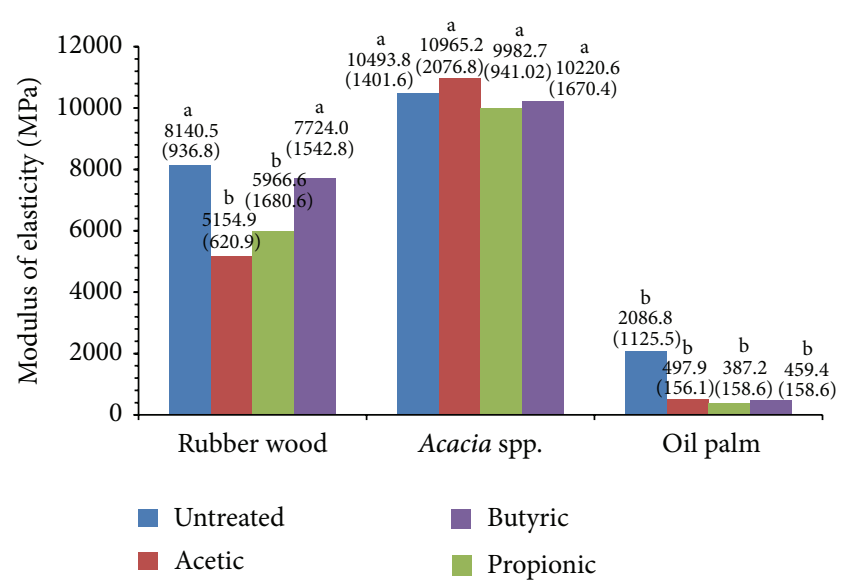

FIGURE 8: The modulus of rupture of woods modified with different anhydrides. Figures in the parentheses are standard deviations. Means followed by the same letter(s) in the same bar are not significantly different at the 0.05 probability level according to the Waller-Duncan test.

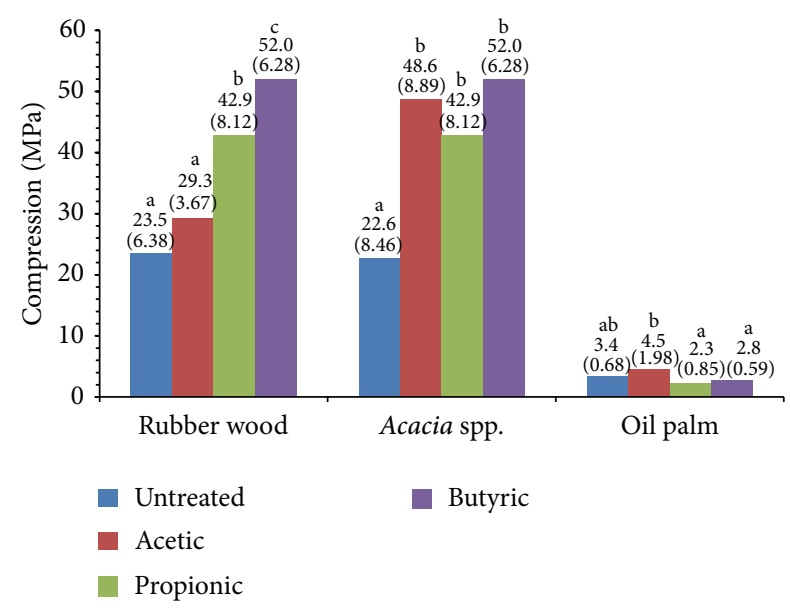

FIGURE 9: The average compression of woods modified with different anhydrides. Figures in the parentheses are standard deviations. Means followed by the same letter(s) in the same bar are not significantly different at the 0.05 probability level according to the Waller-Duncan test.

strength was significantly increased with increasing molecular weight. The highest compression strength was obtained by modifying with butyric anhydride ( $52 \mathrm{MPa})$ followed by propionate anhydride $(42.9 \mathrm{MPa})$ and acetic anhydride (29.3 MPa). In contrast, the average compression strength was not significantly different from the anhydrides in Acacia spp., ranging from 42.9 to $52 \mathrm{MPa}$. However, the average compression strength for all the modified Acacia wood was double that of the untreated wood $(22.6 \mathrm{MPa})$. The Oil palm wood modified with acetic anhydride (4.5 MPa) had significantly higher compression strength than the untreated wood (3.4 MPa). The compression strengths of Oil palm wood modified with propionic $(2.3 \mathrm{MPa})$ and butyric $(2.8 \mathrm{MPa})$ anhydrides were significantly lower than the untreated wood.

The increase in compression strength observed for untreated wood, acetylated wood, propionated wood, and

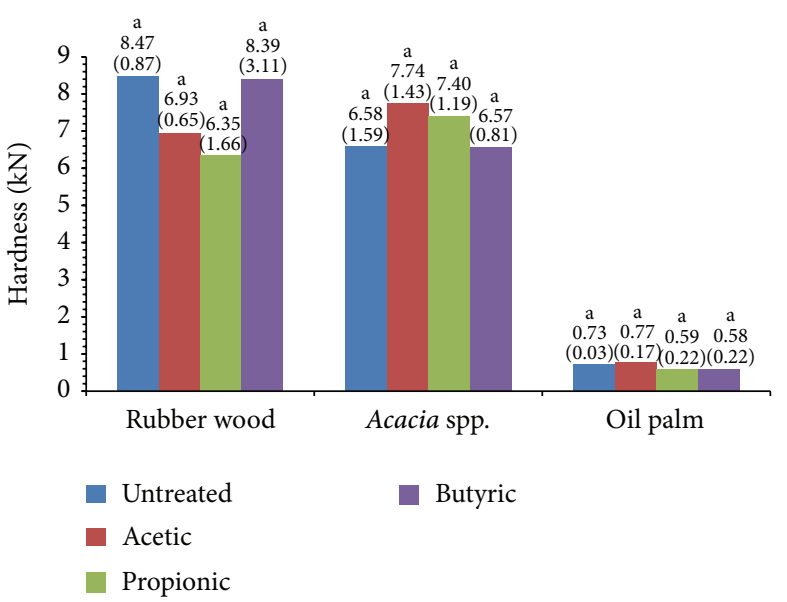

FIGURE 10: The average hardness of woods modified with different anhydrides. Figures in the parentheses are standard deviations. Means followed by the same letter(s) in the same bar are not significantly different at the 0.05 probability level according to the Waller-Duncan test.

butyrylated wood was maybe due to unsubstituted hydroxyl groups which imparts a high tension and compression strengths $[29,30]$. The same findings for modified Corsican pine (Pinus Nigra S.) with acetic, propionic, butyric, valeric, and hexanoic anhydrides were obtained [31]. The compression strength was increased with increasing molecular weight of anhydride due to lower hydroxyl group's substitution for a higher molecular weight of anhydrides since acetic anhydride has the lowest molecular weight and butyric anhydride has the highest molecular weight. The compression strength of wood was mainly contributed by the hemicelluloses and lignin contents followed by cellulose content [32]. Therefore, by referring to Table 1 , higher unsubstituted hydroxyl groups in hemicellulose, lignin, and cellulose will lead to increase the compression strength.

3.2.3. Hardness. The trend of hardness was the same for all wood species (Figure 10). The averages hardness of Rubber wood modified with anhydrides were not significantly different from untreated wood, ranging from 6.35 to $8.47 \mathrm{MPa}$. The hardness was ranged from 6.57 to $7.74 \mathrm{MPa}$ in modified Acacia wood and 0.58 to $0.77 \mathrm{MPa}$ in modified Oil palm wood. The hardness was highest in untreated Rubber wood (8.47 MPa) followed by Acacia wood (6.58 MPa) and Oil palm wood $(0.73 \mathrm{MPa})$. This indicates that the anhydride molecule weight was not influenced by the hardness of modified wood. For comparison, the increase of Brinell hardness strength in acetylated pine was compared to unmodified wood for both tangential and radial surface from 1.82 to 2.28 and from 2.47 to 2.96 , respectively [7]. Lower moisture content of the modified wood was probably the main factor for hardness increment.

3.2.4. Impact Strength. The averages impacts of modified and unmodified wood were shown in Figure 11. Regardless of anhydride, the average impact of modified Rubber wood was 
TABLE 3: The results of correlation test between the basic and physical properties and the mechanical properties of modified wood.

\begin{tabular}{|c|c|c|c|c|c|}
\hline Properties & $\operatorname{MoR}(\mathrm{MPa})$ & $\operatorname{MoE}(\mathrm{MPa})$ & Compression (MPa) & Impact & Hardness \\
\hline \multicolumn{6}{|l|}{ Rubber wood } \\
\hline Uptake (\%) & $-0.15^{\mathrm{Ns}}$ & $-0.14^{\mathrm{Ns}}$ & $-0.23^{\mathrm{Ns}}$ & $-0.26^{\mathrm{Ns}}$ & $0.12^{\mathrm{Ns}}$ \\
\hline Weight gain (\%) & $-0.52^{*}$ & $-0.35^{\mathrm{Ns}}$ & $-0.10^{\mathrm{Ns}}$ & $0.20^{\mathrm{Ns}}$ & $-0.03^{\mathrm{Ns}}$ \\
\hline Bulking coefficient (\%) & $-0.13^{\mathrm{Ns}}$ & $-0.14^{\mathrm{Ns}}$ & $-0.13^{\mathrm{Ns}}$ & $-0.24^{\mathrm{Ns}}$ & $-0.47^{\mathrm{Ns}}$ \\
\hline Density (after modification) & $-0.14^{\mathrm{Ns}}$ & $0.05^{\mathrm{Ns}}$ & $0.10^{\mathrm{Ns}}$ & $0.44^{\mathrm{Ns}}$ & $0.01^{\mathrm{Ns}}$ \\
\hline Density increment & $-0.18^{\mathrm{Ns}}$ & $-0.05^{\mathrm{Ns}}$ & $0.07^{\mathrm{Ns}}$ & $0.13^{\mathrm{Ns}}$ & $0.17^{\mathrm{Ns}}$ \\
\hline Void volume (after modification) & $0.14^{\mathrm{Ns}}$ & $-0.05^{\mathrm{Ns}}$ & $-0.44^{\mathrm{Ns}}$ & $-0.10^{\mathrm{Ns}}$ & $-0.01^{\mathrm{Ns}}$ \\
\hline Void volume changes & $0.17^{\mathrm{Ns}}$ & $-0.02^{\mathrm{Ns}}$ & $-0.22^{\mathrm{Ns}}$ & $-0.06^{\mathrm{Ns}}$ & $-0.13^{\mathrm{Ns}}$ \\
\hline \multicolumn{6}{|l|}{ Acacia spp. } \\
\hline Uptake (\%) & $-0.75^{* *}$ & $-0.64^{*}$ & $-0.48^{\mathrm{Ns}}$ & $-0.41^{\mathrm{Ns}}$ & $-0.45^{\mathrm{Ns}}$ \\
\hline Weight gain (\%) & $-0.80^{* *}$ & $-0.80^{* *}$ & $-0.59^{*}$ & $-0.23^{\mathrm{Ns}}$ & $-0.43^{\mathrm{Ns}}$ \\
\hline Bulking coefficient (\%) & $-0.58^{*}$ & $-0.59^{*}$ & $-0.50^{\mathrm{Ns}}$ & $-0.08^{\mathrm{Ns}}$ & $0.06^{\mathrm{Ns}}$ \\
\hline Density (after modification) & $-0.14^{\mathrm{Ns}}$ & $-0.19^{\mathrm{Ns}}$ & $-0.26^{\mathrm{Ns}}$ & $-0.27^{\mathrm{Ns}}$ & $-0.53^{*}$ \\
\hline Density increment & $-0.48^{\mathrm{Ns}}$ & $-0.48^{\mathrm{Ns}}$ & $-0.42^{\mathrm{Ns}}$ & $-0.25^{\mathrm{Ns}}$ & $-0.55^{*}$ \\
\hline Void volume (after modification) & $0.14^{\mathrm{Ns}}$ & $0.19^{\mathrm{Ns}}$ & $0.26^{\mathrm{Ns}}$ & $0.27^{\mathrm{Ns}}$ & $0.53^{*}$ \\
\hline Void volume changes & $0.38^{\mathrm{Ns}}$ & $0.42^{\mathrm{Ns}}$ & $0.38^{\mathrm{Ns}}$ & $0.09^{\mathrm{Ns}}$ & $0.15^{\mathrm{Ns}}$ \\
\hline \multicolumn{6}{|l|}{ Oil palm } \\
\hline Uptake (\%) & $-0.65^{* *}$ & $-0.64^{* *}$ & $-0.37^{\mathrm{Ns}}$ & $-0.24^{\mathrm{Ns}}$ & $-0.54^{\mathrm{Ns}}$ \\
\hline Weight gain (\%) & $0.40^{\mathrm{Ns}}$ & $0.36^{\mathrm{Ns}}$ & $-0.01^{\mathrm{Ns}}$ & $0.27^{\mathrm{Ns}}$ & $0.07^{\mathrm{Ns}}$ \\
\hline Bulking coefficient (\%) & $-0.21^{\mathrm{Ns}}$ & $-0.25^{\mathrm{Ns}}$ & $-0.04^{\mathrm{Ns}}$ & $-0.14^{\mathrm{Ns}}$ & $0.01^{\mathrm{Ns}}$ \\
\hline Density (after modification) & $0.84^{* *}$ & $0.74^{* *}$ & $0.41^{\mathrm{Ns}}$ & $0.53^{*}$ & $0.62^{*}$ \\
\hline Density increment & $0.39^{\mathrm{Ns}}$ & $0.37^{\mathrm{Ns}}$ & $-0.00^{\mathrm{Ns}}$ & $0.30^{\mathrm{Ns}}$ & $0.06^{\mathrm{Ns}}$ \\
\hline Void volume (after modification) & $-0.84^{* *}$ & $-0.74^{*}$ & $-0.41^{\mathrm{Ns}}$ & $-0.53^{*}$ & $-0.62^{*}$ \\
\hline Void volume changes & $-0.66^{* *}$ & $-0.58^{*}$ & $-0.18^{\mathrm{Ns}}$ & $-0.46^{\mathrm{Ns}}$ & $-0.34^{\mathrm{Ns}}$ \\
\hline
\end{tabular}

Ns: not significant, ${ }^{*}$ significant at the 0.05 level, and ${ }^{* *}$ significant at the 0.01 level.

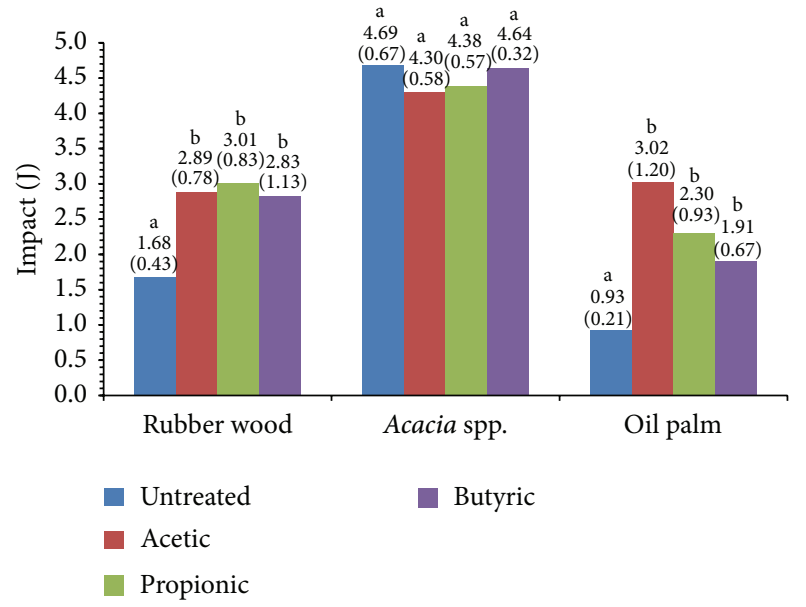

FIGURE 11: The average impact of woods modified with different anhydrides. Figures in the parentheses are standard deviations. Means followed by the same letter(s) in the same bar are not significantly different at the 0.05 probability level according to the Waller-Duncan test.

significantly higher than the untreated wood, ranging from 1.68 to 3.01 Joule. Similarly, the average impact of modified Oil palm wood was significantly higher than the untreated wood, ranging from 0.93 to 3.02 Joule. However, the averages impact of Acacia wood modified with anhydrides were not significantly different from untreated wood, ranging from 4.30 to 4.69 Joule. This indicates that the anhydride molecule weights were not influenced by the impact of modified wood. The increase of impact strength in Rubber and Oil palm woods as compared to the unmodified wood was probably due to increment of density.

3.2.5. The Correlation between the Basic and Physical Properties on the Mechanical Properties of Modified Wood. The correlation test of the basic and physical properties on the mechanical properties is shown in Table 3. The relationship varied between wood species. In Rubber wood, all the basic and physical properties had a weak relation with the MoE, compression, impact, and hardness as seen by the lower $R$ values. However, the WG had a negative $(r=-0.52)$ relation with the MoR. In Acacia wood, the uptake $(r=-0.75$, $r=-0.64)$, WG $(r=-0.87, r=-0.80)$, and bulking coefficient $(r=-0.58, r=-0.59)$ had a negative relation with the MoR and MoE, respectively. The density after modification $(r=-0.53)$ and density increment $(r=-0.53)$ had a negative relation with the hardness. The void volume after modification $(r=0.53)$ had a positive relation with the hardness.

In Oil palm wood, the void volume after modification $(r=-0.84, r=-0.66)$, void volume changes $(r=-0.66$, $r=-0.58)$, and uptake $(r=-0.65, r=-0.64)$ had a negative relation with $\mathrm{MoR}$ and $\mathrm{MoE}$, respectively; but it was reversed 
for density after modification $(r=0.84, r=0.74)$. All the basic and physical properties had a weak relation with compression as depicted by lower $R$ values. The density after modification $(r=0.53$ and $r=0.62)$ had a positive relation with impact and hardness, respectively, but the opposite relation occurred for void volume after modification $(r=-0.53$ and $r=0.62)$.

\section{Conclusion}

Overall, the maximum improvement in terms of mechanical properties is achieved by modifying both Rubber and Acacia woods with butyric anhydride. The modification of Oil palm wood is not suitable with linear chain carboxylic anhydrides due to its poor mechanical properties. The physical properties of modified wood have a low correlation with basic properties for all species. The correlation between physical and mechanical properties of modified wood is dependent on species.

\section{Conflict of Interests}

The authors declare that there is no conflict of interests regarding the publication of this paper.

\section{References}

[1] M. D. Thomas and R. J. Peterson, "Protection of wood from decay fungi by acetylation-an ultrastructural and chemical study," Wood and Fibre, vol. 10, no. 3, pp. 149-163, 1978.

[2] C. A. S. Hill, Wood Modification: Chemical, Thermal and Other Processes, John Wiley \& Sons, England, UK, 2006.

[3] S. Kumar, "Chemical modification of wood," Wood and Fiber Science, vol. 26, no. 2, pp. 270-280, 1994.

[4] R. M. Rowell, "Acetylation of wood: journey from analytical technique to commercial reality," Forest Products Journal, vol. 56, no. 9, pp. 4-12, 2006.

[5] H. P. M. Bongers and E. P. Beckers, "Mechanical properties of acetylated solid wood treated on pilot plant scale," in Proceedings of the 1st Europen Conference on Wood Modification, J. van Acker and C. A. S. Hill, Eds., pp. 341-350, Ghent, Belgium, 2003.

[6] A. Jorissen, F. Bongers, B. Kattenbroek, and W. Homan, "The influence of acetylation of Radiata pine in structural sizes on its strength properties," in Proceedings of 2nd European Conference on Wood Modification, H. Militz and C. A. S. Hill, Eds., pp. 108116, Gottingen, Germany, 2005.

[7] P. Larsson and R. Simonson, "A study of strength, hardness and deformation of acetylated Scandinavian softwoods," Holz als Roh- und Werkstoff, vol. 52, no. 2, pp. 83-86, 1994.

[8] P. L. Brelid and R. Simonson, "Acetylation of solid wood using microwave heating: part 2. Experiments in laboratory scale," Holz als Roh- und Werkstoff, vol. 57, no. 5, pp. 383-389, 1999.

[9] K. K. Pandey, M. Hughes, and T. Vuorinen, "Dimensional stability, UV resistance, and static mechanical properties of Scots pine chemically modified with alkylene epoxides," BioResources, vol. 5, no. 2, pp. 598-615, 2010.

[10] R. M. Rowell and W. B. Banks, "Tensile strength and toughness of acetylated pine and lime flakes," British Polymer Journal, vol. 19, no. 5, pp. 479-482, 1987.
[11] C. Birkinshaw and M. D. Hale, "Mechanical properties and fungal resistance af acetylated fast grown softwood. I . Small specimens," Irish Forestry, vol. 59, no. 1-2, pp. 49-58, 2002.

[12] M. J. Ramsden, F. S. R. Blake, and N. J. Fey, "The effect of acetylation on the mechanical properties, hydrophobicity and dimensional stability of Pinus sylvestris," Wood and Science Technology, vol. 31, pp. 97-104, 1997.

[13] J. L. Bowyer, R. Shmulsky, and J. G. Haygreen, Forest Products and Wood Science: An Introduction, Iowa State University Press, Ames, Iowa, USA, 4th edition, 2003.

[14] British Standards Institution, Methods of Testing Small Clear Specimens of Timber, vol. 373, 1957.

[15] C. A. S. Hill and D. Jones, "Dimensional changes in Corsican pine sapwood due to chemical modification with linear chain anhydrides," Holzforschung, vol. 53, no. 3, pp. 267-271, 1999.

[16] N. H. Hamid and M. Hale, "Decay threshold of acetylated rattan against white and brown rot fungi," International Wood Products Journal, vol. 3, no. 2, pp. 96-106, 2012.

[17] R. M. Rowell, "Distribution of reacted chemicals in southern pine treated with methyl isocyanate," Wood Science, vol. 13, no. 2, pp. 102-110, 1980.

[18] R. M. Rowell, "Distribution of acetyl groups in southern pine reacted with acetic anhydride," Wood Science, vol. 15, no. 2, pp. $172-182,1982$.

[19] R. M. Rowell, "Penetration and reactivity of cell wall components," in The Chemistry of Solid Wood, R. M. Rowell, Ed., vol. 207 of Advances in Chemistry Series, pp. 175-210, American Chemical Society, 1984.

[20] A. J. Stamm, Wood and Cellulose Science, Ronald Press, New York, NY, USA, 1964.

[21] P. Larsson Brelid, R. Simonson, and P. O. Risman, "Acetylation of solid wood using microwave heating: part 1: studies of dielectric properties," Holz als Roh- und Werkstoff, vol. 57, no. 4, pp. 259-263, 1999.

[22] J.-Z. Li, T. Furuno, S. Katoh, and T. Uehara, "Chemical modification of wood by anhydrides without solvents or catalysts," Journal of Wood Science, vol. 46, no. 3, pp. 215-221, 2000.

[23] H. L. Thong and S. H. Choh, Rubberwood: Processing and Utilisation, Forest Research Institute Malaysia, Kepong, Malaysia, 1994.

[24] P. C. Pinto, D. V. Evtuguin, and C. P. Neto, "Chemical composition and structural features of the macromolecular components of plantation Acacia mangium wood," Journal of Agricultural and Food Chemistry, vol. 53, no. 20, pp. 7856-7862, 2005.

[25] H. P. S. A. Khalil, M. S. Alwani, R. Ridzuan, H. Kamarudin, and A. Khairul, "Chemical composition, morphological characteristics, and cell wall structure of Malaysian oil palm fibers," Polymer-Plastics Technology and Engineering, vol. 47, no. 3, pp. 273-280, 2008.

[26] K. Minato, R. Takazawa, and K. Ogura, "Dependence of reaction kinetics and physical and mechanical properties on the reaction systems of acetylation II: physical and mechanical properties," Journal of Wood Science, vol. 49, no. 6, pp. 519-524, 2003.

[27] A. N. Papadopoulos, "The effect of acetylation on bending strength of finger jointed beech wood (Fagus sylvatica L.)," Holz als Roh- und Werkstoff, vol. 66, no. 4, pp. 309-310, 2008.

[28] R. M. Rowell, "Chemical modification of wood," Commonwealth Forestry Bureau, Forest Product Abstract, vol. 6, no. 12, pp. 363-382, 1983. 
[29] J. M. Dinwoodie, Timber: Its Nature and Behaviour, E. \& F.N. Spon, London, UK, 2nd edition, 2000.

[30] A. J. Panshin and C. DeZeeuw, Textbook of Wood Technology, McGraw-Hill, 4th edition, 1980.

[31] A. N. Papadopoulos and G. Pougioula, "Mechanical behaviour of pine wood chemically modified with a homologous series of linear chain carboxylic acid anhydrides," Bioresource Technology, vol. 101, no. 15, pp. 6147-6150, 2010.

[32] P. Larsson Brelid, R. Simonson, Ö. Bergman, and T. Nilsson, "Resistance of acetylated wood to biological degradation," Holz als Roh- und Werkstoff, vol. 58, no. 5, pp. 331-337, 2000. 

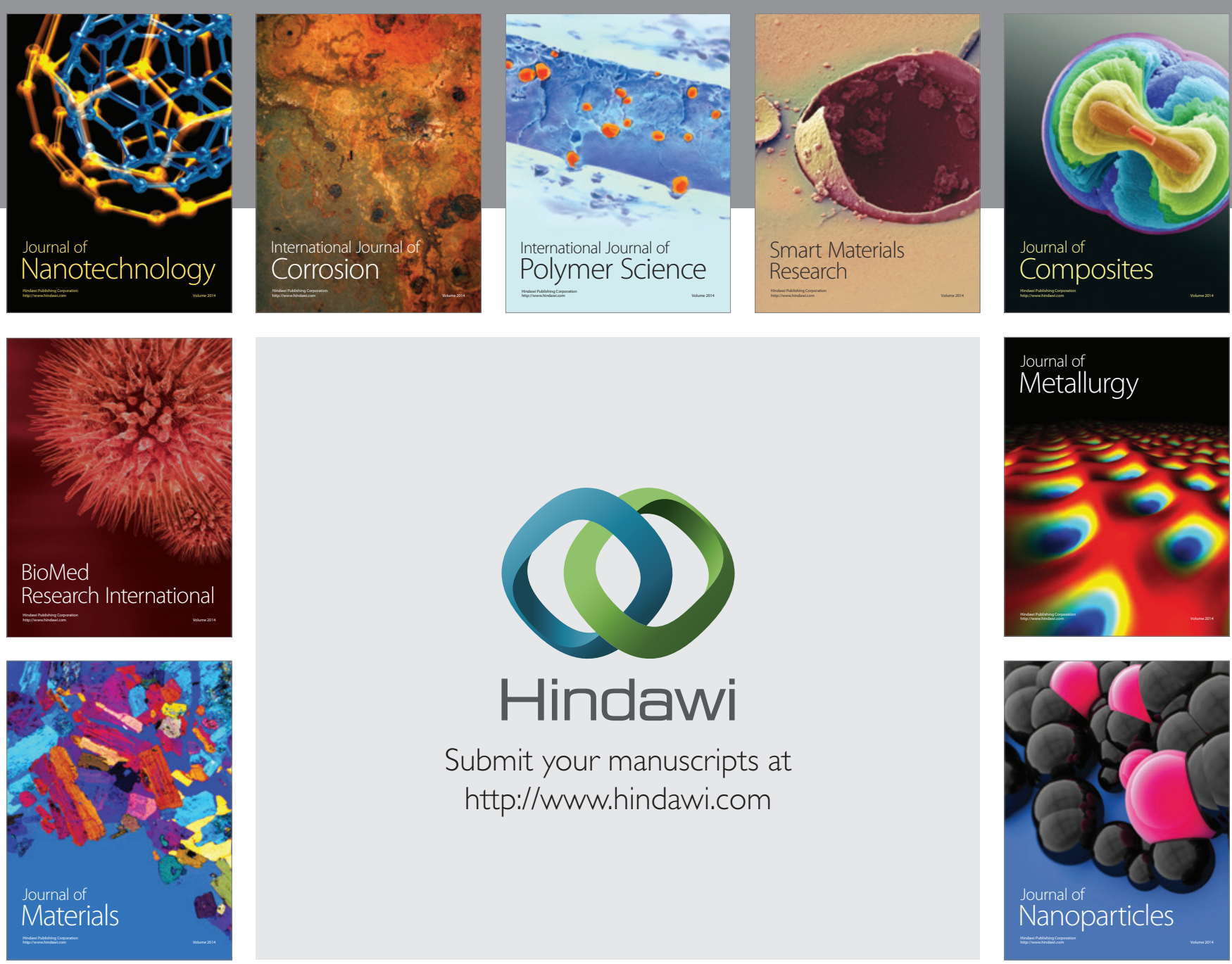

Submit your manuscripts at http://www.hindawi.com
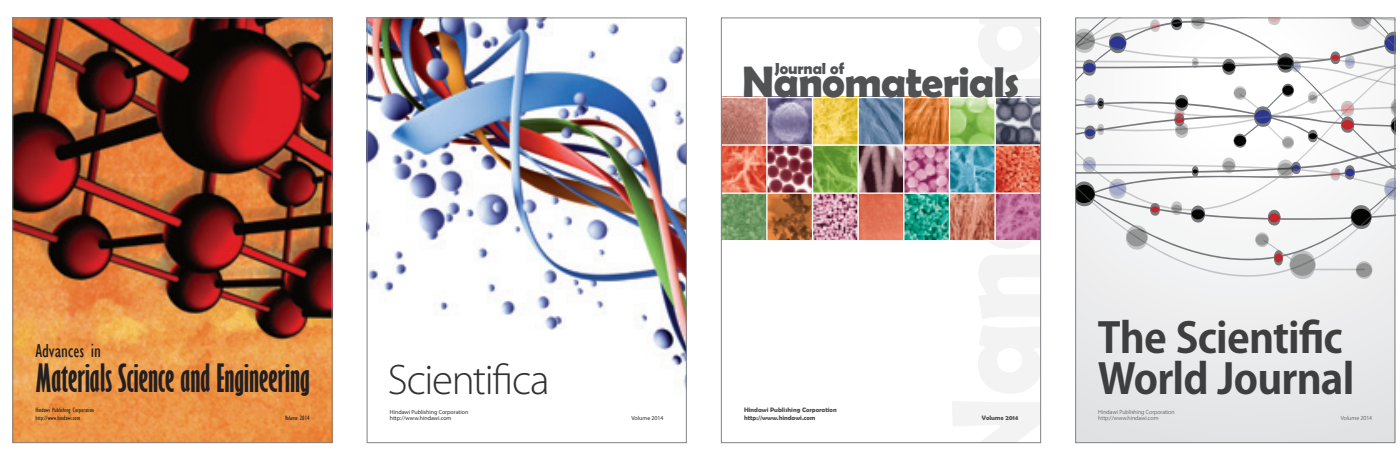

\section{The Scientific World Journal}
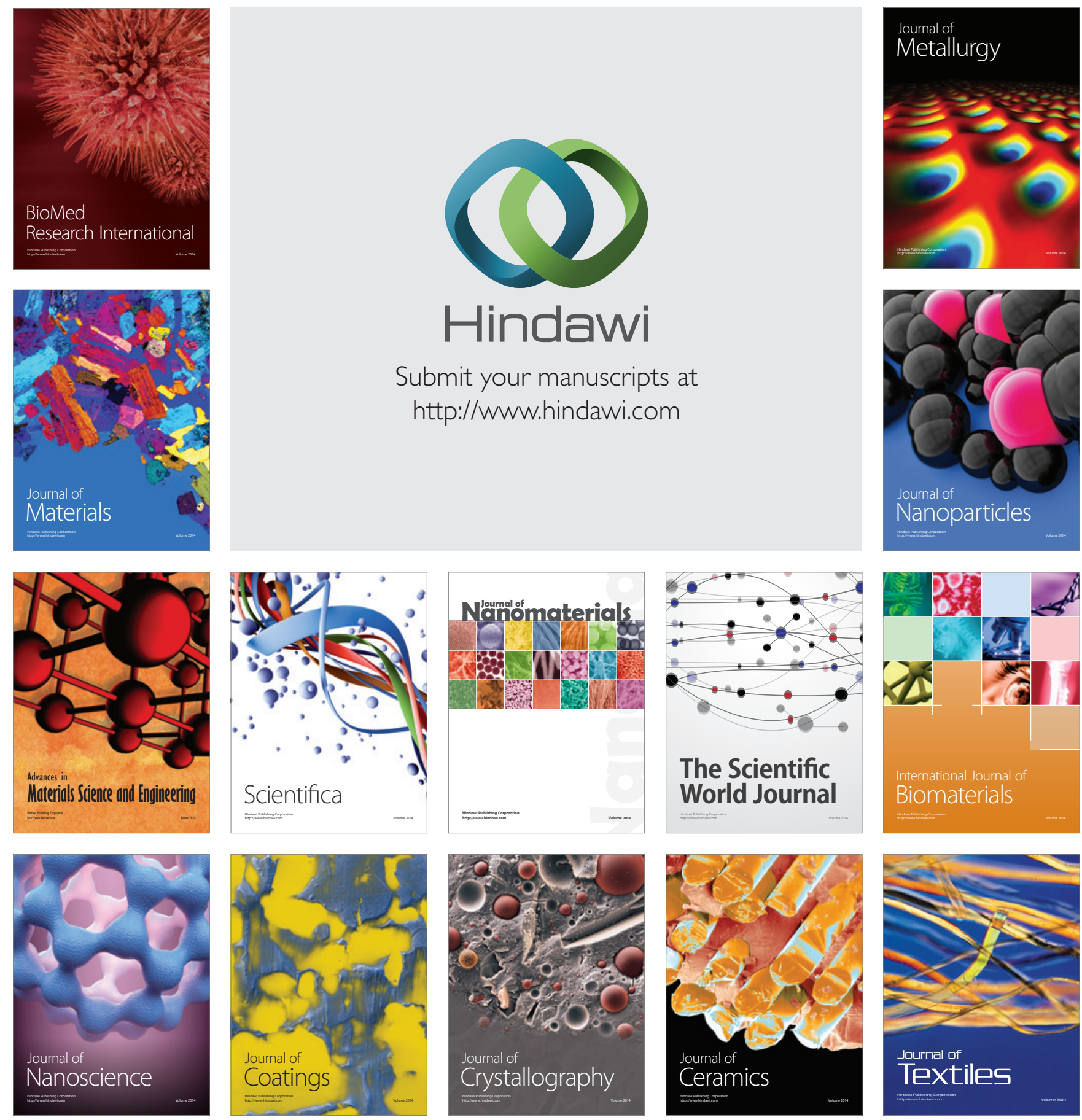